\title{
Phodopus campbelli detect reduced photoperiod during development but, unlike Phodopus sungorus, retain functional reproductive physiology
}

\author{
Mary E Timonin, Ned J Place ${ }^{1}$, Esther Wanderi ${ }^{1}$ and Katherine E Wynne-Edwards \\ Department of Biology, Queen's University, Kingston, Ontario, Canada K7L 3N6 and ${ }^{1}$ Department of Population \\ Medicine and Diagnostic Sciences, College of Veterinary Medicine, Cornell University, Ithaca, New York 14853, USA \\ Correspondence should be addressed to KEWynne-Edwards; Email: wynneedw@biology.queensu.ca
}

\begin{abstract}
Golden (Mesocricetus auratus) and Siberian (Phodopus sungorus) hamsters are widely used as animal models for seasonal reproduction; but $M$. auratus shows no developmental delay in short days until after sexual maturity, whereas $P$. sungorus juveniles delay development in short days. As the photoperiodic response of Phodopus campbelli is not well established, litters of the two Phodopus species were gestated and reared under long days (14 h light:10 h darkness) or short days (10 h light:14 h darkness) until 70 days of age. As expected, under short photoperiod $P$. sungorus showed reduced body, testes, epididymides, uterus, and ovary weight; antral follicles and corpora lutea were absent and vaginae remained closed. Animals moulted to winter pelage, and low concentrations of each of leptin, testosterone, and prolactin were present in male serum. Phodopus campbelli juveniles also responded to the short photoperiod as measured by reduced body, testes, epididymides, and ovary weight. The summer pelage persisted. However, both sexes of $P$. campbelli developed functional reproduction under $10 \mathrm{~h}$ light:14 h darkness. All females had a patent vagina by 10 weeks; ovaries contained antral follicles and corpora lutea, and uteri were not reduced in weight. In males, the concentrations of testosterone, leptin, and prolactin were not reduced by short photoperiod. Developmental patterns in the three species of hamster, therefore, differ and are not predicted by relatedness or latitude of origin. Other ecological traits, such as predictability of summer rainfall, ambient temperature, and differential responses to social cues might be important.

Reproduction (2006) 132 661-670
\end{abstract}

\section{Introduction}

Directional changes in photoperiod act as a proximal cue for the coming season, allowing animals to anticipate environmental changes (Goldman 2001). Juvenile Siberian dwarf hamsters, Phodopus sungorus, raised under short photoperiods $(\leq 12 \mathrm{~h}$ light) have slowed growth, decreased reproductive development, and delayed puberty compared with controls maintained in long photoperiods ( $\geq 14 \mathrm{~h}$ light; Hoffmann 1978, Yellon \& Goldman 1984, Furuta et al. 1994, Shaw \& Goldman 1995, Hegstrom \& Breedlove 1999b, Adam et al. 2000). In contrast, the golden hamster (Mesocricetus auratus) exhibits a robust reproductive response to short photoperiod as an adult. In juveniles, the growth, development, and the timing of puberty are not affected by rearing in short photoperiod or total darkness (Darrow et al. 1980).

The closest living relative of $P$. sungorus is the Djungarian dwarf hamster, Phodopus campbelli (Ross 1995, 1998, Sokolov et al. 1998). The two species are not sympatric but experience similar photoperiods, because they are found at similar latitudes in middle Asia and Siberia (Flint 1966). However, the habitat of $P$. campbelli is harsher, with less rainfall during a shorter breeding season, and colder winter temperatures (Wynne-Edwards 1998). There is also evidence that juvenile $P$. campbelli have less sensitivity to reduce photoperiod than juvenile P. sungorus (Ebling 1994). In juvenile $P$. campbelli, short-day rearing did not significantly reduce body weight, testes or uterine weight, or prolactin concentration at 70 days age (Ebling 1994). Therefore, it is possible that ecological differences, independent of latitude or phylogenetic history, contribute to developmental responses to short photoperiod. However, the $P$. campbelli animals used in the Ebling (1994) study were derived from the pet trade (Wright's of Essex), and might not be representative of the wild population.

The present study was, therefore, designed to confirm and extend the results of Ebling (1994) with outbred 
laboratory populations of each species, descended from wild-caught individuals (Wynne-Edwards 1995, 2003), which retain species differences in activity and social behavior as seen in the field (Wynne-Edwards 1995, 2003, Wynne-Edwards et al. 1999). Reproductive development in $P$. campbelli and $P$. sungorus raised from conception in either a long day $(L D=14 \mathrm{~h}$ light:10 h darkness) or a short day (SD $=10 \mathrm{~h}$ light:14 h darkness), were compared to determine the time course and effects of reduced photoperiod on body weight, reproductive development, puberty, and serum hormone levels.

\section{Methods}

\section{Animals}

Sexually naïve, male and female $P$. sungorus and $P$. campbelli, aged 60-110 days at the beginning of the study, were drawn from a breeding colony that consists of the outbred descendants of wild-caught individuals maintained at Queen's University since 1990 (WynneEdwards 1995). Housing mimics conditions seen in the P. campbelli breeding season in its natural habitat (Wynne-Edwards 1998) with temperatures $18 \pm 1.0^{\circ} \mathrm{C}$, to reflect typical burrow temperatures and photoperiod of $14 \mathrm{~h}$ light:10 $\mathrm{h}$ darkness $(0000 \mathrm{~h}$ corresponding to the middle of the dark phase). Animals were housed in samesexed sibling groups of one to three individuals from the time of weaning (18 days) until pairing. Standard caging $(27 \times 21 \times 14 \mathrm{~cm}$ polycarbonate cages; Nalge Nunc International, Rochester, NY, USA) was used at all stages of these studies. Food (Rodent Diet 5001; LabDiet, Richmond, IN, USA) and fresh tap water were available ad libitum. All animal care procedures complied with the guidelines set out by the Canadian Council on Animal Care under Queen's University protocols 2004-065 and 2005-011.

\section{Photoperiod manipulation}

Twenty-four breeding pairs of $P$. campbelli and $P$. sungorus were established using standard procedures for this breeding colony that minimize inbreeding and provide a slight weight advantage to the male. Half of the pairs were moved to an experimental photoperiod $(10 \mathrm{~h}$ light:14 $\mathrm{h}$ darkness) on the day of pairing and the rest were maintained under standard photoperiod $(14 \mathrm{~h}$ light:10 $\mathrm{h}$ darkness). Litters produced by these pairs were reared under the same photoperiod as their parents. Females that did not give birth within 32 days after pairing were excluded from the study. Young were weaned at 18 days of age into same-sex sibling groups of one to four individuals. No attempt was made to track individual identity within a litter.

\section{Developmental measures}

During lactation, pups were sexed and weighed at ages 12,15 , and 18 days. Results were reduced to an average for male and female pups in the litter before analysis. After weaning, individuals in cage-groups were weighed weekly until 70 days of age. Vaginal patency was scored as open or closed in female cage-groups, every 2 days, beginning with the day of weaning. Once all females in the cage had been consistently scored as patent (4 successive times) vaginal patency was checked only weekly. Pelage color was scored weekly, beginning on the day of weaning (18 days of age), using a four-point scale (Duncan \& Goldman 1984) that ranged from summer pelage (1) to a white winter coat with a remaining dark dorsal stripe (4).

\section{Hormone assays}

At 70 days age, serum was collected from males during the light phase, using a method that does not induce handling-related changes in cortisol or prolactin (Reburn \& Wynne-Edwards 2000). Animals were anesthetized with remotely administered isoflurane (1-chloro-2,2,2trifluroethyl difluromethyl ether) vaporized in oxygen. Multiple cages were anesthetized at a time, with no new animals introduced into the sampling room until all carcasses and soiled cages were removed from the room. This precaution was taken to reduce 'spectator effects', which alter prolactin levels (Reburn \& Wynne-Edwards 2000). Blood (1.0-1.3 ml) was drawn from the retroorbital sinus using a non-heparinized Pasteur pipette. Samples were stored at $4{ }^{\circ} \mathrm{C}$ overnight, centrifuged for 10 min at $4{ }^{\circ} \mathrm{C}$, and the resulting serum was stored at $-20^{\circ} \mathrm{C}$ until assayed for hormone content.

Each serum sample had the concentration of testosterone, leptin, and prolactin determined. To avoid effects of repeated freeze-thaw cycles, testosterone and leptin were quantified over a 2-day period. At the same time, serum for prolactin assay was diluted into assay buffer to yield the $100 \mu \mathrm{l}$ volume required for the assay, and then re-frozen. Both species and photoperiod manipulations were represented in each assay. Results for multiple males within the same litter were averaged before analyses, so that the independent sample size was the number of litters in each treatment.

Total testosterone concentration was determined using a ${ }^{125}$ I double antibody kit (Coat-A-Count total testosterone; Diagnostics Products Corporation, Intermedico, Markham, Ontario, Canada). Samples and pools were analyzed in duplicate at $50 \mu \mathrm{l}$ in two assays. Three human serum controls (CON4, CON5, and CON6; Intermedico) fell within expected ranges, yielding intraassay coefficient of variation (CV) estimates between 3 and $13 \%$ and inter-assay CV estimates between 7 and $9 \%$. Blood pools from sexually naïve male hamsters contained $10.5 \mathrm{ng} / \mathrm{ml}$ (P. campbelli) and $6.2 \mathrm{ng} / \mathrm{ml}$ 
(P. sungorus), with intra-assay $\mathrm{CV}$ between 4 and $9 \%$ and inter-assay CV of $8 \%$. The range of the assay was $0.02-$ $32 \mathrm{ng} / \mathrm{ml}$, with interpolated values outside those limits rounded to the limit before analyses. In practice, 11 samples fell below the lower limit and four samples exceeded the upper limit.

Leptin concentration was determined using a ${ }^{125}$ I double antibody kit (Multispecies Leptin Kit; Linco Research, Incorporated, St Charles, MO, USA), previously validated in Phodopus (Horton et al. 2000). Samples and pools were analyzed in duplicate at $50 \mu \mathrm{l}$ and standards were analyzed in triplicate at $100 \mu \mathrm{l}$ in two assays on the same day. Purified recombinant human leptin (6000K QC1 and QC2) and blood pools from naïve hamsters of each species were used as internal controls. All human controls were inside the expected range with intra-assay CV of 22 and 19\% (QC1) and 13 and $23 \%$ (QC2) and inter-assay CV of 23 and $21 \%$ respectively. Homologous serum pools fell at $5.9 \mathrm{ng} / \mathrm{ml}$ (P. campbelli) and $9.9 \mathrm{ng} / \mathrm{ml}$ (P. sungorus) of human equivalent, with intra-assay $\mathrm{CV}$ of $20,4,12$, and $2 \%$ respectively. Inter-assay CV was $18 \%$ (P. campbelli) and $9 \%$ ( $P$. sungorus). No samples fell outside the $2-100 \mathrm{ng} / \mathrm{ml}$ interpolation range.

Prolactin concentration was determined using ${ }^{125} \mid$ heterologous golden hamster prolactin (Dr A F Parlow, Pituitary Hormones and Antisera Center, Harbor-UCLA Research and Education Institute, Los Angeles, CA, USA) as routinely used for these species (McMillan \& Wynne-Edwards 1999, Reburn \& Wynne-Edwards 1999, 2000, Brooks et al. 2005). Rat-anti-hamster prolactin (\#AFP-7472988) was the primary antibody and goat-anti-rat gamma globulin (titer P4 lot \#9TA814; Antibodies, Inc., Davis, CA, USA) was the secondary antibody. Hamster prolactin (\#AFP-10302E) was used as a reference standard. Assay sensitivity ranged from 0.02 to $10 \mathrm{ng} / \mathrm{ml}$. Ten microliters of samples and control pools were diluted into a $100 \mu \mathrm{l}$ volume with assay buffer and assayed in triplicate against a triplicate standard curve. Three assays were from a single iodination. Intra-assay $\mathrm{CV}$ was 41,44 , and $39 \%$ at $0.04 \mathrm{ng} / \mathrm{ml}$ and 51,6 , and $3 \%$ at $2.5 \mathrm{ng} / \mathrm{ml}$. Inter-assay CV for those two controls was 44 and $30 \%$ respectively. Interpolations outside the detection limits were rounded to the limiting value. In practice, nine determinations fell below the lower limit and none fell above.

\section{Measures at 70 days}

Males were killed immediately following blood collection, while still under isoflurane anesthesia. Body weight was recorded and then testes and epididymides were cleared of surrounding fat and weighed to yield a paired fresh weight. Pelage score was also noted.

Females were killed by cervical dislocation without anesthesia, since no blood sample was taken. Vaginal patency, paired ovarian weight, and uterine fresh weight were recorded. Ovaries and uteri were immediately fixed in $10 \%$ buffered neutral formalin and serially dehydrated into $70 \%$ ethanol. Twenty-four ovaries, selected at random to represent six individuals from different litters within each of the four groups, were embedded in paraffin, serially sectioned at $6 \mu \mathrm{m}$, and stained with hematoxylin and eosin. An investigator, blind to species and group status, counted ovarian follicles in every tenth section, with a random start between the fourth and sixth sections, and classified follicles as primordial, transitional, primary, secondary, or antral. Primordial follicles were defined as an ooctye surrounded by a single layer of flattened granulosa cells, whereas transitional follicles contained a mix of flattened and cuboidal granulosa cells. Transitional follicles are considered to be part of the pool of primordial follicles, because this class of follicle consists of both slow growing and non-growing follicles (Meredith et al. 2000). Primary follicles had a single layer of cuboidal granulosa cells and secondary follicles had multiple layers of cuboidal granulosa cells. A follicle with an antrum of any size was classified as an antral follicle. To ensure that follicles were counted only once, visualization of a healthy oocyte nucleus was required for inclusion. Presence or absence of functional or atretic corpora lutea was also recorded.

\section{Statistical analyses}

All statistics were carried out using JMP version 5.0.1 (SAS Institute, Cary, NC, USA). For measures, such as body and tissue weights, data were normally distributed and analyzed by ANOVA, with repeated measures and adjustment for unequal variances where appropriate. Vaginal patency was compared with non-parametric approaches. The number of antral follicles or corpora lutea was transformed to remove zeros $(\log (x+1))$ before analysis. Details are indicated in the results. All measures applied a critical $\alpha$ of 0.05 .

\section{Results \\ Reproductive success}

Out of 48 breeding pairs that started the experiment, 41 gave birth within 32 days and were included in the study. Across the two species, females on short days were less likely to deliver a litter (Fisher exact $P=0.02$ ), although the effect was not significant within either species ( $P$. campbelli long day $=12$, short day $=10$, Fisher exact $P=0.48 ; P$. sungorus long day $=12$, short day $=8$ (although one litter was killed, leaving $N=7$ ), Fisher exact $P=0.09$ ). Litter size at birth did not differ across treatments (species $P=0.76$; photoperiod $P=0.58$; interaction $P=0.76$ ) and there was no evidence of differences in pup survival to weaning (pups lost: species $P=0.87$; photoperiod $P=0.48$; interaction $P=0.99$ ). 
There was also no evidence for a differential latency to deliver the first litter with 37/41 females delivering litters conceived within one estrous cycle (4 days) of pairing (species $P=0.22$; photoperiod $P=0.15$; interaction $P=0.18$ ).

\section{Pup weight}

Although pup survival was not altered, pup weight before weaning (repeated measure across days 12, 15, and 18; $\left.F_{2,275}=3.59, P<0.0001\right)$ had additional effects of species $\left(F_{1,275}=5.62, \quad P<0.005\right)$ and pup sex $\left(F_{1,275}=4.33, \quad P<0.02\right)$ but not photoperiod $\left(F_{1,275}=1.00, P=0.37\right)$. However, there was also a significant three-way interaction over species, photoperiod, and pup sex $(P<0.0001)$ with two-way interactions across species and photoperiod $(P<0.001)$, but not sex and species $(P=0.08)$ or sex and photoperiod $(P=1.00)$. Within $P$. sungorus, there was a sexual dimorphism in body weight at day 12 with females larger than males (male weight/female weight: P. campbelli 0.96; $P$. sungorus 0.71$)$, but this was eliminated by day 15 ( $P$. campbelli 1.03; P. sungorus 1.02) and later turned into a shared dimorphism of about $15 \%$ in favor of males $(P$. campbelli 1.16; P. sungorus 1.17). As a result, analyses of weight from days 12 to 70 after birth considered sex, species, and photoperiod (Fig. 1).

Males grew over the ten repeated weight measurements from days 12 to 67 after birth $\left(F_{9,24}=151, P<\right.$ $0.0001)$ with significant interactions with species $\left(F_{1,24}=5.72, P<0.0005\right)$ and photoperiod $\left(F_{1,24}=4.00\right.$, $P<0.005)$ and a three-way interaction term $(P=0.02)$. Therefore, from days 25 to 67 , male $P$. campbelli housed under long days were heavier than male $P$. campbelli housed under short days. Those male $P$. campbelli housed under short days were similar in weight to male $P$. sungorus housed under long days. $P$. sungorus males housed under long days were also heavier than $P$. sungorus males housed under short days (Fig. 1a). Within each species, the males differed in the timing of a photoperiod effect. Long-day P. campbelli males were heavier than short-day males on day 18 (one-way ANOVA within day with post hoc Tukey-Kramer honestly significant difference (HSD)), but the effect was not significant until day 32 for $P$. sungorus males.

Females also grew over the ten repeated weight measurements from days 12 to 67 after birth $\left(F_{9,21}=\right.$ $170, P<0.0001)$ with significant interactions with species $\left(F_{1,21}=16.7, P<0.0001\right)$ and photoperiod $\left(F_{1,21}=3.68, P<0.01\right)$ and a three-way interaction term $(P<0.05)$. The order of the groups was similar to the males, although female $P$. campbelli housed under long days were not significantly heavier than female $P$. campbelli housed under short days. Those female $P$. campbelli housed under short days were similar in weight to female $P$. sungorus housed under long days, and all groups were heavier than $P$. sungorus females

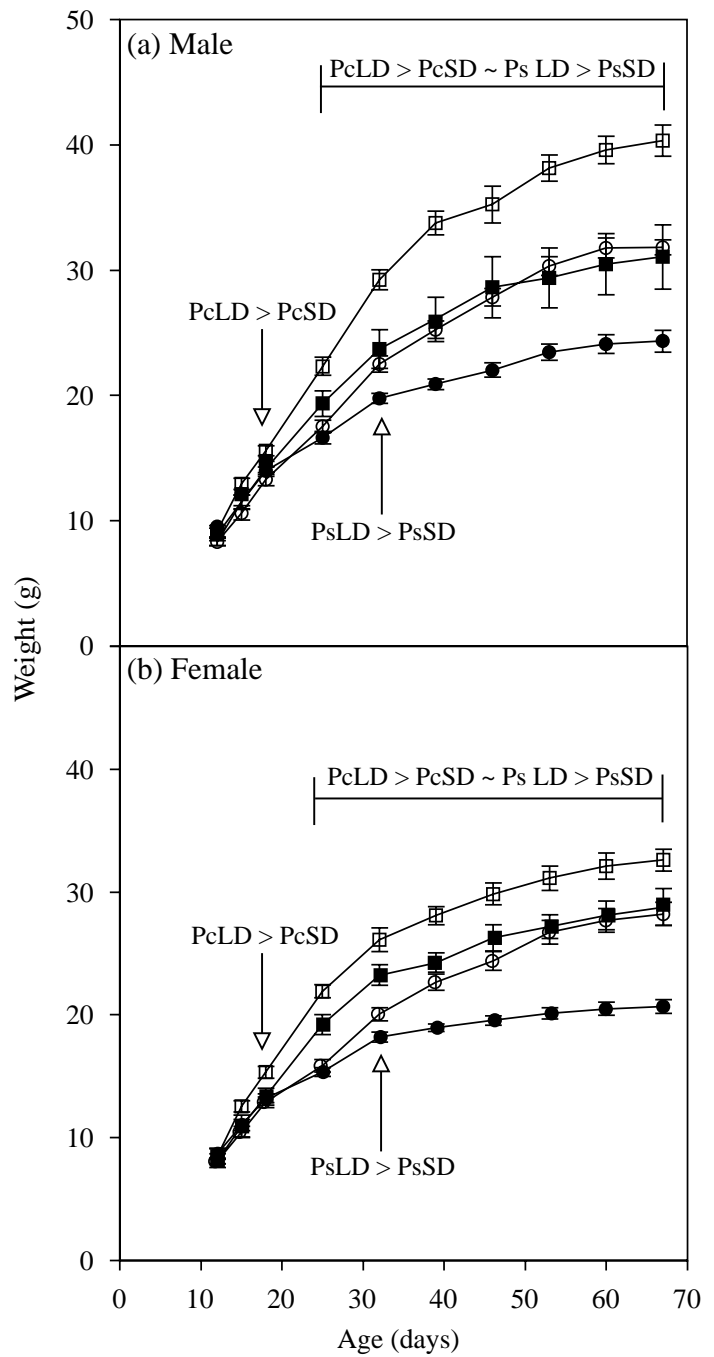

Figure 1 Body weight ( $\mathrm{g} \pm$ s.E.M.) for Phodopus campbelli (Pc; squares) and Phodopus sungorus (Ps; circles) (a) males and (b) females gestated and raised under a photoperiod of $10 \mathrm{~h}$ light: $14 \mathrm{~h}$ darkness (short day (SD); closed symbols) or the typical housing photoperiod of $14 \mathrm{~h}$ light: $10 \mathrm{~h}$ darkness (long day (LD); open symbols). The age at which long- and short-day first differed is indicated for each species by a vertical arrow. The bracket encloses the age interval over which species and photoperiod differences persisted, as indicated by the inequalities.

housed under short days (Fig. 1b). The species difference in weight was established by day 18 (one-way ANOVA within day with post hoc Tukey-Kramer HSD). As seen for the males, long-day P. campbelli females were heavier than short-day females at day 18 , but the photoperiod difference within $P$. sungorus females was not seen until day 32 .

\section{Reproductive development}

Latency to the first female with a vaginal patency is shown in Fig. $2 a$, with latency until all females in the cage had patent vaginae shown in Fig. $2 b$. Under long days, the first $P$. campbelli female was patent within 1 


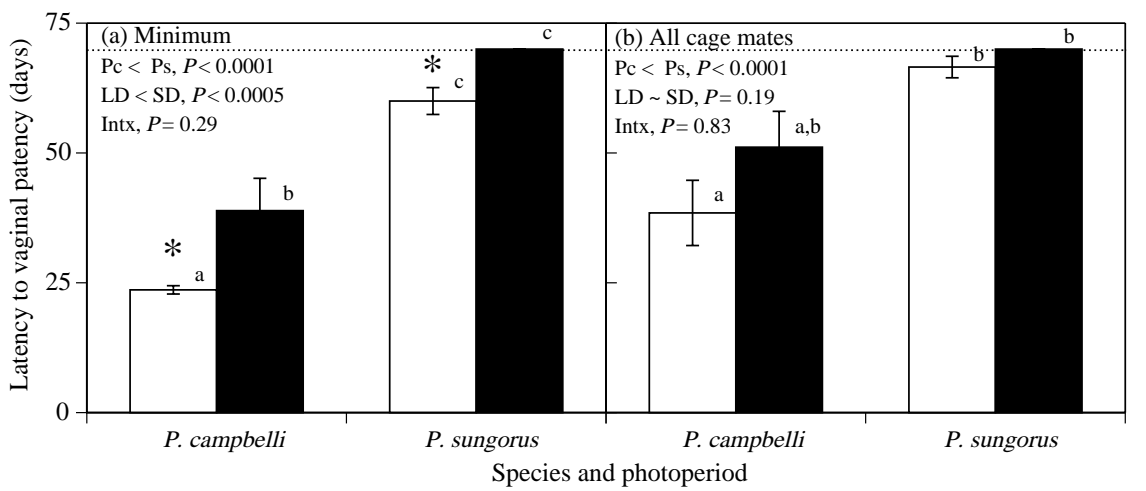

Figure 2 Mean age at vaginal patency (days \pm S.E.M.) for (a) the first female in a cage, and (b) all females in a cage for $P$. campbelli and $P$. sungorus females housed since conception in long days (14 h light:10 h darkness; open bars) or short days (10 h light:14 h darkness; black bars). Significant effects of species, photoperiod, or the interaction of species and photoperiod are indicated as inequalities. Post hoc differences within a species across groups are indicated by different lower case letters. Post hoc differences within a species are indicated by*. Data at 70 days should be interpreted as $\geq 70$ days. week of weaning ( $23.6 \pm 0.8$ days). This latency doubled under short days $(40.9 \pm 6.1$ days; $t=-2.8, \mathrm{df}=18$, $P<0.01)$. However, the difference did not persist when the latency measure required all females in the cage to be patent, because three cage-groups failed to reach the criterion under long days (long days $40.3 \pm 6.6$, short days $48.6 \pm 6.4 ; z=1.00, P=0.32$ ). In contrast, only 9 of 11 long-day $P$. sungorus groups had a single patent female by day 70 , and this was later than long-day $P$. campbelli females $(z=3.96, P<0.0001)$. No short-day $P$. sungorus females reached vaginal patency by 70 days. This was later than long-day females $(z=3.01$, $P<0.005)$, but we cannot provide an accurate estimate of the age to reach this developmental stage in P. sungorus.

In males the rate of reproductive development was estimated by testes (Fig. 3a) and epididymides (Fig. 3b) paired fresh weight at 70 days. Testes were larger in $P$. campbelli than $P$. sungorus $\left(F_{1,37}=58.7, P<0.0001\right)$ and larger under the long photoperiod $\left(F_{1,37}=42.4\right.$,
$P<0.0001)$ with an interaction $(P<0.02)$, because the proportional reduction in weight under short days was greater for $P$. sungorus. Results were similar for epididymides (Fig. 3 b). For both measures in P. sungorus males, the decline in tissue weight was proportional to the decline in overall body weight, so that there was no effect of photoperiod if the tissue weight was expressed as a proportion of body weight. In contrast, the effect of photoperiod in $P$. campbelli persisted after correction for body weight (testes $P<0.002$; epididymides $P<0.002$ ).

Fresh weight of the paired ovaries and the uterus was examined in females. At 70 days, P. campbelli ovaries were significantly heavier than $P$. sungorus ovaries $\left(F_{1,37}=41.8, \quad P<0.0001\right)$, and ovarian weight was greater under long days $\left(F_{1,37}=15.6, P<0.0005\right)$ with no interaction ( $P=0.73$; Fig. $3 c$ ). Results were similar for uterine weight with a $31 \%$ reduction in uterine weight under short days for $P$. campbelli and a $71 \%$ reduction under short days for P. sungorus (Fig. $3 d$ ).

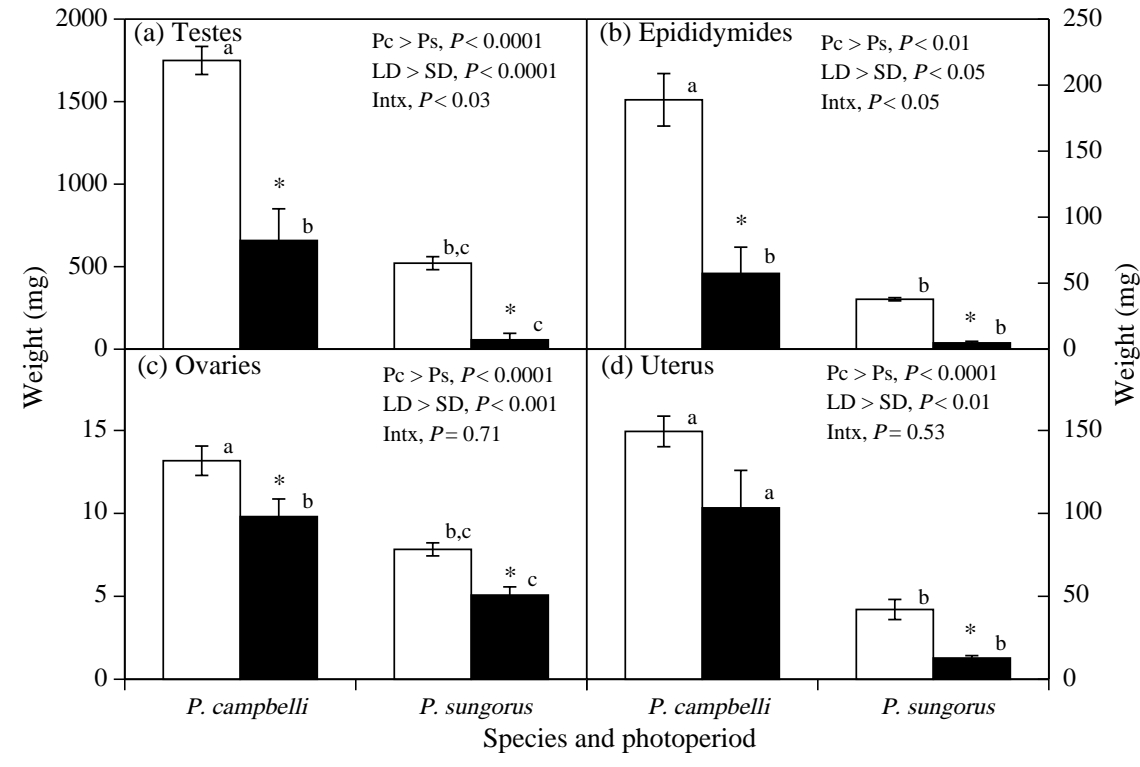

Figure 3 Paired fresh weight (mg \pm s.E.M.) at 70 days of age for (a) testes, (b) epididymides, (c) ovaries, and (d) uterus; for male (a and b) and female (c and d) $P$. campbelli and $P$. sungorus housed since conception in long days (14 h light:10 h darkness (LD); open bars) or short days (10 $\mathrm{h}$ light:14 $\mathrm{h}$ darkness (SD); black bars). Significant effects of species, photoperiod, or the interaction of species and photoperiod are indicated as inequalities with post hoc differences (Tukey-Kramer HSD) indicated by lower case letter and post hoc differences within a species indicated by *. 


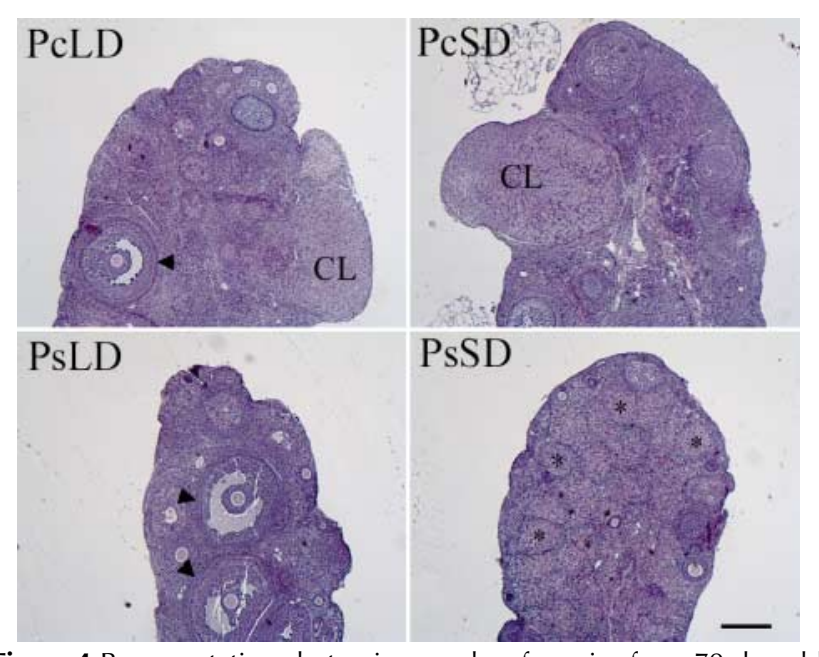

Figure 4 Representative photomicrographs of ovaries from 70-day-old $P$. campbelli $(\mathrm{Pc})$ or $P$. sungorus (Ps) maintained in a long-day $(14 \mathrm{~h}$ light:10 $\mathrm{h}$ darkness (LD)) or short-day (10 h light:14 h darkness (SD)) photoperiod. Antral follicles (arrowheads) and/or corpora lutea (CL) were observed in both long- and short-day P. campbelli ovaries as well as long-day $P$. sungorus ovaries, but not short-day ovaries from $P$. sungorus females. In addition, the short-day ovaries from $P$. sungorus females contained clusters of large eosinophilic cells (indicated by *). Sections were stained with hematoxylin and eosin and photographed at a magnification of $50 \times$. Bar $=100 \mu \mathrm{m}$.

Ovarian follicular development was further advanced in P. campbelli than P. sungorus, regardless of photoperiod (Fig. 4). Five of six ovaries from P. campbelli had at least one antral follicle and/or corpus luteum (CL), whereas only half the ovaries from $P$. sungorus held under long days had antral follicles and none had $\mathrm{CL}$ (Table 1). Follicular development was never advanced beyond the preantral stage (secondary follicles), when $P$. sungorus were held under short days. Numbers of antral follicles were greater in $P$. campbelli than $P$. sungorus $\left(F_{1,20}=16.7, P<0.001\right)$, with no effect of day length $(P=$ $0.19)$ and no interaction term $(P=0.45)$. No significant differences were detected across other follicle types. Under short days, P. sungorus ovaries not only lacked antral follicles and corpora lutea, but also contained multiple nests or clusters of large eosinophilic cells (Fig. 4). An atretic oocyte was often centrally located within these clusters, suggesting that these large cells were hypertrophied granulosa cells from an atretic follicle.

As a previous study had noted that there was a depletion of the resting $P$. sungorus follicular pool (primordial plus transitional follicles) under long days that did not occur under short days (Place et al. 2004), the size of the follicular pool was also compared. In $P$. sungorus females under short days, the pool was somewhat larger $(72 \%)$ than the primordial follicle pool in females under long days, although the difference did not achieve statistical significance $(z=-1.9, P=0.06)$.

\section{Pelage}

There was no change in pelage for any $P$. campbelli litters over the 70 days of this experiment. All remained in their full summer pelage $(1.0 \pm 0)$. As expected, $P$. sungorus under long photoperiod also remained in their summer pelage throughout the 70 days $(1.0 \pm 0)$. In contrast, $5 / 7$ short-day $P$. sungorus litters were already at a pelage score of 2 at 25 days of age, all seven litters had a pelage score of 2 at 60 days, and two litters had moved to a pelage score between 2 and 3 by 67 days of age. Thus, $P$. sungorus pelage responded to the reduced photoperiod, but $P$. campbelli pelage did not.

\section{Hormones in male serum}

Serum testosterone levels were significantly higher in $P$. campbelli than $P$. sungorus males $\left(F_{1,37}=6.30\right.$, $P<0.02)$ with no evidence for a photoperiod effect $\left(F_{1,37}=2.29, P=0.14\right)$ and no interaction $(P=0.80$; Fig. 5a). Serum leptin levels were significantly higher in $P$. campbelli than $P$. sungorus males regardless of treatment group $\left(F_{1,37}=6.60, P<0.02\right)$ with no evidence for a photoperiod effect $\left(F_{1,37}=0.57, P=0.45\right)$ although there was a significant interaction $(P<0.01)$, because the $P$. campbelli on short photoperiod had higher leptin than the $P$. sungorus males on short days (post hoc TukeyKramer HSD; Fig. 5b). Prolactin levels did not differ across the two species $\left(F_{1,37}=0.03, P=0.87\right)$, but were significantly reduced by short days $\left(F_{1,37}=19.3\right.$, $P<0.0001)$ with a significant interaction $(P<0.05)$, because the $P$. sungorus long-day male levels were

Table 1 Ovarian follicular development at 70 days.

\begin{tabular}{|c|c|c|c|c|c|c|c|}
\hline Group & Primordial & Trans & Primary & Secondary & Antral & Corpora lutea $^{a}$ & Primordial + trans \\
\hline $\begin{array}{l}\text { P. campbelli } 14 \mathrm{~h} \\
\text { light: } 10 \mathrm{~h} \text { darkness }\end{array}$ & $160.5 \pm 34.7$ & $3.5 \pm 1.0$ & $33.7 \pm 6.5$ & $10.8 \pm 3.0$ & $2.3 \pm 0.7$ & $5 / 6$ & $164.0 \pm 35.2$ \\
\hline $\begin{array}{l}\text { P. campbelli } 10 \mathrm{~h} \\
\text { light: } 14 \mathrm{~h} \text { darkness }\end{array}$ & $149.7 \pm 16.9$ & $3.8 \pm 2.1$ & $31.7 \pm 5.6$ & $12.0 \pm 2.8$ & $1.8 \pm 0.5$ & $4 / 6$ & $153.5 \pm 18.7$ \\
\hline $\begin{array}{l}\text { P. sungorus } 14 \mathrm{~h} \\
\text { light: } 10 \mathrm{~h} \text { darkness }\end{array}$ & $131.5 \pm 19.9$ & $3.2 \pm 0.9$ & $26.2 \pm 3.1$ & $12.7 \pm 2.6$ & $0.7 \pm 0.3$ & $0 / 6$ & $134.7 \pm 19.5$ \\
\hline $\begin{array}{l}\text { P. sungorus } 10 \mathrm{~h} \\
\text { light: } 14 \mathrm{~h} \text { darkness }\end{array}$ & $225.7 \pm 44.6$ & $5.7 \pm 1.8$ & $33.3 \pm 5.6$ & $8.7 \pm 2.1$ & 0 & $0 / 6$ & $231.3 \pm 46.2$ \\
\hline
\end{tabular}

${ }^{\mathrm{a}}$ Corpora lutea counts represent the number of females in each group that had CLs present at the time of counting. 


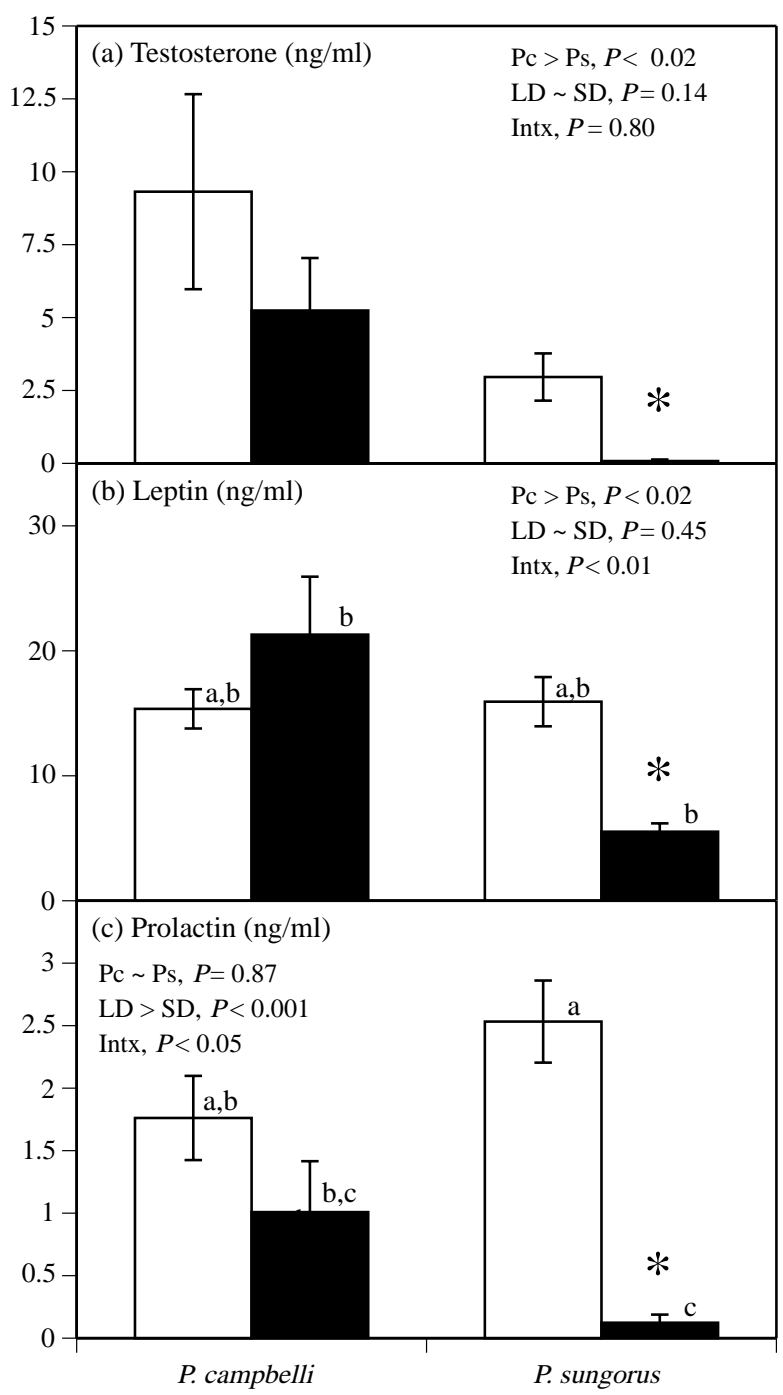

Figure 5 Concentration (mean \pm s.E.M.) of (a) testosterone $(\mathrm{ng} / \mathrm{ml}$ ), (b) leptin $(\mathrm{ng} / \mathrm{ml})$, and (c) prolactin $(\mathrm{ng} / \mathrm{ml})$ in serum collected under isoflurane anesthesia from 70-day-old Phodopus campbelli (Pc) and Phodopus sungorus (Ps) males housed since conception in long days (14 h light:10 h darkness (LD); open bars) or short days (10 h light:14 h darkness (SD); black bars). Significant effects of species, photoperiod, or the interaction of species and photoperiod are indicated as inequalities with post hoc differences (Tukey-Kramer HSD) indicated by lower case letter and post hoc differences within a species indicated by *.

significantly higher than those for both species of males experiencing short days (Fig. 5c).

\section{Discussion}

When exposed to a reduced photoperiod of $10 \mathrm{~h}$ light:14 $\mathrm{h}$ darkness throughout gestation and development, as opposed to a permissive photoperiod of $14 \mathrm{~h}$ light:10 h darkness, both male and female juvenile $P$. sungorus responded as expected. Testes and epididymides, as well as uteri and ovaries, remained small under $10 \mathrm{~h}$ light:14 h darkness (Hoffmann 1978, Yellon
\& Goldman 1984, Ebling 1994, Furuta et al. 1994, Hegstrom \& Breedlove 1999b, Adam et al. 2000, van den Hurk et al. 2002), and ovaries did not contain antral follicles or corpora lutea (van den Hurk et al. 2002, Place et al. 2004). No females held under $10 \mathrm{~h}$ light:14 h darkness displayed vaginal opening by 70 days of age (Adam et al. 2000, Place et al. 2004). Body weight diverged with both males and females under $10 \mathrm{~h}$ light: $14 \mathrm{~h}$ darkness at reduced body weight relative to the $14 \mathrm{~h}$ light: $10 \mathrm{~h}$ darkness animals (Yellon \& Goldman 1984, Ebling 1994, Hegstrom \& Breedlove 1999b, Adam et al. 2000, van den Hurk et al. 2002), and male leptin concentration significantly reduced relative to $14 \mathrm{~h}$ light:10 h darkness (Atcha et al. 2000, Horton et al. 2000, Klingenspor et al. 2000). Pelage moulted to the winter white (Hoffmann 1978). Testosterone and prolactin concentrations were also low in $10 \mathrm{~h}$ light:14 h darkness males relative to $14 \mathrm{~h}$ light: $10 \mathrm{~h}$ darkness males (Yellon \& Goldman 1984, Ebling 1994, Furuta et al. 1994).

As expected, based on responses of adults to short days (Mercer et al. 1994, 1995a, 1995b, Bilbo et al. 2003), P. campbelli also detected the reduced photoperiod, as measured by reduced testes, epididymides, and ovary weight. Body weight was also reduced as a result of short photoperiod exposure, however, unlike $P$. sungorus males, serum leptin levels were unaffected by short photoperiod in P. campbelli. As fat pads were not assessed, this species difference in leptin response remains difficult to interpret (Mercer et al. 1994, 1995a, Atcha et al. 2000, Klingenspor et al. 2000, Bartness et al. 2002). Although changing pelage in $P$. campbelli adults exposed to short days has been reported (Bilbo et al. 2003), summer pelage did not change with gestation and juvenile development under reduced photoperiod. Reproductive suppression, in contrast to $P$. sungorus, was minimal in both sexes of $P$. campbelli under reduced photoperiod. Specifically, the concentration of testosterone and prolactin in males was not reduced under $10 \mathrm{~h}$ light: $14 \mathrm{~h}$ darkness relative to $14 \mathrm{~h}$ light: $10 \mathrm{~h}$ darkness, all females developed to vaginal patency within 10 weeks, ovaries contained antral follicles and corpora lutea, and uteri were not reduced in weight. Thus, the species differences previously described within a population derived from the pet-trade (Ebling 1994), were confirmed and extended to this population derived from wild-caught individuals.

With our measures of reproductive development at 70 days, we cannot distinguish between (a) slower growth of $P$. campbelli reproductive tissues under $10 \mathrm{~h}$ light:14 $\mathrm{h}$ darkness than $14 \mathrm{~h}$ light:10 $\mathrm{h}$ darkness and (b) similar early growth trajectories for $P$. campbelli in the 2 day lengths followed by regression of reproductive tissues in the reduced photoperiod group. This latter pattern is typical of the responses of juvenile golden hamster (M. auratus) to gestation in long days, and 
rearing in short days (Gaston \& Menaker 1967, Darrow et al. 1980). The earlier study comparing these two species of Phodopus, however, also included measures of reproductive tissues at 35 days in addition to measures at 70 days (Ebling 1994). In that study, although body weight was not affected by photoperiod, $P$. campbelli testes weight and uterine weight at 35 days were reduced under $8 \mathrm{~h}$ light: $16 \mathrm{~h}$ darkness relative to $16 \mathrm{~h}$ light: $8 \mathrm{~h}$ darkness (Ebling 1994). Therefore, the developmental pattern for reproductive tissues in $P$. campbelli is not the same as the 'develop and then regress' pattern described for golden hamsters (Darrow et al. 1980). Thus, the developmental trajectories for reproduction in $P$. campbelli did not follow established patterns for $P$. sungorus or the golden hamster.

Despite the close phylogenetic relatedness of these sibling species within the genus Phodopus (Ross 1995, 1998, Sokolov et al. 1998), and their similar latitude of origin (Flint 1966, which determines annual photoperiod), the photoperiod responsiveness of $P$. campbelli was not predicted by known responses of $P$. sungorus to reduced photoperiod. Thus, it is likely that local ecological variables have been of greater importance than absolute photoperiod or ancestry in determining the reproductive responses to reduced photoperiod.

In particular, the two species of Phodopus differ in the harshness of their environment. The habitat in which $P$. campbelli is found has colder winters (January average of $-30^{\circ} \mathrm{C}$ rather than $\left.-20^{\circ} \mathrm{C}\right)$, less rainfall $(210 \mathrm{~mm}$ vs $300 \mathrm{~mm}$ annually), and a shorter season during which rain falls (2 months rather than 5 months; Wynne-Edwards 1998, 2003). Thus, one hypothesis would predict that $P$. campbelli would wait for longer days before initiating reproduction because the rain occurs later in the summer and early breeding is not likely to be successful. However, these data do not support that hypothesis, because these juvenile $P$. campbelli activate reproduction even under a day length of $10 \mathrm{~h}$ that is typically seen in May and September. An alternate hypothesis is that the breeding season of $P$. campbelli is less predictable than the $P$. sungorus breeding season because rain is ephemeral and cannot be accurately predicted by photoperiod. If so, then photoperiod might broadly indicate time of year, but be a less salient predictor of ideal breeding conditions that is supplemented by other variables such as succulent food or rainfall to determine the timing of breeding attempts.

Responses to $14 \mathrm{~h}$ light: $10 \mathrm{~h}$ darkness also suggest that reproductive development in $P$. campbelli is insensitive to photoperiod relative to $P$. sungorus. For P. campbelli, all measures of development in the present study were similar to equivalent measures under $16 \mathrm{~h}$ light: $8 \mathrm{~h}$ darkness in the earlier comparative study (Ebling 1994). In contrast, reproductive development in both sexes of $P$. sungorus was reduced relative to reproductive development at $16 \mathrm{~h}$ light:8 h darkness (Ebling 1994). This was consistent with studies showing that $16 \mathrm{~h}$ light:8 $\mathrm{h}$ darkness promotes more rapid development than $14 \mathrm{~h}$ light:10 $\mathrm{h}$ darkness in P. sungorus (Gorman 1995). Thus, choice of $16 \mathrm{~h}$ light: $8 \mathrm{~h}$ darkness, rather than $14 \mathrm{~h}$ light: $10 \mathrm{~h}$ darkness as the long-day photoperiod would probably have enhanced measures of long-day reproductive development in $P$. sungorus without altering measures of reproductive development in P. campbelli.

There might, however, be additional contributing environmental factors to the species difference, such as ambient temperature. In the semi-desert where $P$. campbelli is found, low temperatures in the night that are cool $\left(4-12{ }^{\circ} \mathrm{C}\right)$, even when the summer days are at their hottest (unpublished local weather records for Erzin, Tuva). This reduces soil temperature so that burrows that are approximately $1 \mathrm{~m}$ deep remain cool throughout the summer (approx $18{ }^{\circ} \mathrm{C}$; Wynne-Edwards 1998, 2003). Breeding P. campbelli females are intolerant of ambient temperatures typically used to house laboratory rodents $\left(23^{\circ} \mathrm{C}\right)$ and suffer maternal hyperthermia (Scribner \& Wynne-Edwards 1994a, 1994b) that constrains pup attendance (Walton \& Wynne-Edwards 1997) and reduces pup survival (Wynne-Edwards \& Lisk 1988) relative to an ambient temperature of $18{ }^{\circ} \mathrm{C}$. For this reason, the populations studied here are, and have been, maintained at an ambient temperature of $18{ }^{\circ} \mathrm{C}$ (Wynne-Edwards \& Lisk $1988,1989)$. This ambient temperature is cooler than $23^{\circ} \mathrm{C}$ typically used to house $P$. sungorus in other laboratories (Lerchl \& Schlatt 1993, Gorman 1995, Bilbo et al. 2003) and might have slowed developmental trajectories in response to the increased metabolic demands of thermoregulation at the lower ambient temperature.

In addition, cues from conspecifics might have contributed to the species differences seen. In $P$. sungorus, males remain reproductively competent under short days if housed with a cycling female (Hegstrom \& Breedlove 1999a, Park et al. 2004, Timonin \& Wynne-Edwards 2006). Thus, it is possible that cues from P. campbelli females supported the developmental trajectory of males under $10 \mathrm{~h}$ light: $14 \mathrm{~h}$ darkness and/or cues from P. campbelli males supported the developmental trajectory of females. A species difference in the salience of social cues is not unlikely, because the two species of Phodopus differ in social organization. Phodopus campbelli show obligate bi-parental care that includes acting as a midwife during the delivery of a litter (Jones \& Wynne-Edwards 2000, 2001) and prompt retrieval of an experimentally displaced pup (Reburn \& Wynne-Edwards 1999, Brooks et al. 2005, Hume \& Wynne-Edwards 2005, 2006, Schum \& Wynne-Edwards 2005, Vella et al. 2005), whereas $P$. sungorus shows none of the same paternal responsiveness (Reburn \& Wynne-Edwards 1999, Schum \& Wynne-Edwards 2005, Timonin \& Wynne-Edwards 2006). Thus, reproductive development in spite of 
detection of reduced photoperiod, might reflect an interaction between stimulatory and inhibitory environmental cues that have greater salience for $P$. campbelli than for P. sungorus (e.g. Duncan et al. 1985, Masuda \& Oishi 1988, Nelson et al. 1989).

Clearly, important differences in developmental responses to gestation and juvenile development under reduced photoperiod characterize $P$. sungorus, $M$. auratus, and P. campbelli. The exceptional photoperiodism of $P$. sungorus is not shared by its closest living relative, even though that relative inhabits similar latitudes (WynneEdwards 1995, 1998, 2003, Wynne-Edwards et al. 1999). The golden hamster strategy of reproductive development irrespective of photoperiod, followed by regression in response to reduced photoperiod, also fails to generalize to P. campbelli. Latitudinal shifts in range are likely to be required in the face of global climate change (Parmesan 1996, Thomas et al. 2004, Wilson et al. 2005). Given the diversity of responses to photoperiod contained within the hamster clade, we should not overestimate our ability to predict the responses of species and communities to shifting climate on the basis of relatedness, ecological similarity, or results from a few model organisms.

\section{Acknowledgements}

This research was supported by a Natural Sciences and Engineering Research Council (NSERC) Discovery Grant to KEWE and an NSERC Postgraduate Scholarship to MET. The authors declare that there is no conflict of interest that would prejudice the impartiality of this scientific work.

\section{References}

Adam CL, Moar KM, Logie TJ, Ross AW, Barrett P, Morgan PJ \& Mercer JG 2000 Photoperiod regulates growth, puberty and hypothalamic neuropeptide and receptor gene expression in female Siberian hamsters. Endocrinology 141 4349-4356.

Atcha Z, Cagampang FRA, Stirland JA, Morris ID, Brooks AN, Ebling FJP, Klingenspor M \& Loudon ASI 2000 Leptin acts on metabolism in a photoperiod-dependent manner, but has no effect on reproductive function in the seasonally breeding Siberian hamster (Phodopus sungorus). Endocrinology 141 4128-4135.

Bartness TJ, Demas GE \& Song CK 2002 Seasonal changes in adiposity: the roles of the photoperiod, melatonin and other hormones, and sympathetic nervous system. Experimental Biology and Medicine (Maywood) 227 363-376.

Bilbo SD, Dhabhar FS, Viswanathan K, Saul A \& Nelson RJ 2003 Photoperiod affects the expression of sex and species differences in leukocyte number and leukocyte trafficking in congeneric hamsters. Psychoneuroendocrinology 28 1027-1043.

Brooks PL, Vella ET \& Wynne-Edwards KE 2005 Dopamine agonist treatment before and after the birth reduces prolactin concentration but does not impair paternal responsiveness in Djungarian hamsters, Phodopus campbelli. Hormones and Behavior 47 358-366.

Darrow JM, Davis FC, Elliott JA, Stetson MH, Turek FW \& Menaker M 1980 Influence of photoperiod on reproductive development in the golden hamster. Biology of Reproduction 22 443-450.

Duncan MJ \& Goldman BD 1984 Hormonal regulation of the annual pelage color cycle in the Djungarian hamster, Phodopus sungorus. II. The role of prolactin. Journal of Experimental Zoology 230 97-103.
Duncan MJ, Goldman BD, Di Pinto MN \& Stetson MH 1985 Testicular function and pelage color have different critical daylengths in the Djungarian hamster, Phodopus sungorus. Endocrinology 116 424-430.

Ebling FJ 1994 Photoperiodic differences during development in the dwarf hamsters Phodopus sungorus and Phodopus campbelli. General and Comparative Endocrinology 95 475-482.

Flint WE 1966 Die Zwerghamster der Paläarktischen Fauna. Wittenberg Lutherstadt: A. Ziemsen Verlag.

Furuta I, Porkka-Heiskanen T, Scarbrough K, Tapanainen J, Turek FW \& Hsueh AJW 1994 Photoperiod regulates testis cell apoptosis in Djungarian hamsters. Biology of Reproduction 51 1315-1321.

Gaston S \& Menaker M 1967 Photoperiodic control of hamster testis. Science 158 925-928.

Goldman BD 2001 Mammalian photoperiodic system: formal properties and neuroendocrine mechanisms of photoperiodic time measurement. Journal of Biological Rhythms 16 283-301.

Gorman MR 1995 Seasonal adaptations of Siberian hamsters. I. Accelerated gonadal and somatic development in increasing versus static long day lengths. Biology of Reproduction 53 110-115.

Hegstrom CD \& Breedlove SM 1999a Social cues attenuate photoresponsiveness of the male reproductive system in Siberian hamsters (Phodopus sungorus). Journal of Biological Rhythms $\mathbf{1 4}$ 54-61.

Hegstrom CD \& Breedlove SM $1999 b$ Short day lengths affect perinatal development of the male reproductive system in the Siberian hamster, Phodopus sungorus. Journal of Biological Rhythms $\mathbf{1 4}$ 402-408.

Hoffmann K 1978 Effects of short photoperiods on puberty, growth and moult in the Djungarian hamster (Phodopus sungorus). Journal of Reproduction and Fertility $\mathbf{5 4} 29-35$.

Horton TH, Buxton OM, Losee-Olson S \& Turek FW 2000 Twenty-fourhour profiles of serum leptin in Siberian and Golden hamsters: photoperiodic and diurnal variations. Hormones and Behavior 37 388-398.

Hume JM \& Wynne-Edwards KE 2005 Castration reduces male testosterone, estradiol, and territorial aggression, but not paternal behavior in biparental dwarf hamsters (Phodopus campbelli). Hormones and Behavior 48 303-310.

Hume JM \& Wynne-Edwards KE 2006 Paternal responsiveness in biparental dwarf hamsters (Phodopus campbelli) does not require estradiol. Hormones and Behavior 49 538-544.

Jones JS \& Wynne-Edwards KE 2000 Paternal hamsters mechanically assist the delivery, consume amniotic fluid and placenta, remove fetal membranes, and provide parental care during the birth process. Hormones and Behavior 37 116-125.

Jones JS \& Wynne-Edwards KE 2001 Paternal behaviour in biparental hamsters does not require contact with the pregnant female. Animal Behaviour 62 453-464.

Klingenspor M, Niggemann H \& Heldmaier G 2000 Modulation of leptin sensitivity by short photoperiod acclimation in the Djungarian hamster, Phodopus sungorus. Journal of Comparative Physiology B $17037-43$.

Lerchl A \& Schlatt S 1993 Influence of photoperiod on pineal melatonin synthesis, fur color, body weight, and reproductive function in the female Djungarian hamster, Phodopus sungorus. Neuroendocrinology 57 359-364.

Masuda A \& Oishi T 1988 Effects of photoperiod and temperature on body weight, food intake, food storage, and pelage color in the Djungarian hamster, Phodopus sungorus. Journal of Experimental Zoolology 248 133-139.

McMillan HJ \& Wynne-Edwards KE 1999 Divergent reproductive endocrinology of the estrous cycle and pregnancy in dwarf hamsters (Phodopus). Comparative Biochemistry and Physiology A 124 53-67.

Mercer JG, Duncan JS, Lawrence CB \& Trayhurn P 1994 Effect of photoperiod on mitochondrial GDP binding and adenylate cyclase activity in brown adipose tissue of Djungarian hamsters. Physiology and Behavior 56 737-740. 
Mercer JG, Lawrence CB \& Morgan PJ 1995a Fat mobilisation in short days is not associated with altered noradrenergic sensitivity of adipocytes in Djungarian hamsters. Physiology and Behavior 57 249-253.

Mercer JG, Lawrence CB, Beck B, Burlet A, Atkinson T \& Barrett P $1995 b$ Hypothalamic NPY and prepro-NPY mRNA in Djungarian hamsters: effects of food deprivation and photoperiod. American Journal of Physiology 269 R1099-R1106.

Meredith S, Dudenhoeffer G \& Jackson K 2000 Classification of small type B/C follicles as primordial follicles in mature rats. Journal of Reproduction and Fertility 119 43-48.

Nelson RJ, Frank D, Smale L \& Willoughby SB 1989 Photoperiod and temperature affect reproductive and nonreproductive functions in male prairie voles (Microtus ochrogaster). Biology of Reproduction 40 481-485.

Park JH, Takasu N, Alvarez MI, Clark K, Aimaq R \& Zucker I 2004 Long-term persistence of male copulatory behavior in castrated and photo-inhibited Siberian hamsters. Hormones and Behavior 45 214-221.

Parmesan C 1996 Climate and species' range. Nature 382 765-766.

Place NJ, Tuthill CR, Schoomer EE, Tramontin AD \& Zucker I 2004 Short day lengths delay reproductive aging. Biology of Reproduction 71 987-992.

Reburn CJ \& Wynne-Edwards KE 1999 Hormonal changes in males of a naturally biparental and a uniparental mammal. Hormones and Behavior 35 163-176.

Reburn CJ \& Wynne-Edwards KE 2000 Cortisol and prolactin concentrations during repeated blood sample collection from freely moving, mouse-sized mammals (Phodopus spp.). Comparative Medicine 50 184-198.

Ross PD 1995 Phodopus campbelli. Mammalian Species 503 1-7.

Ross PD 1998 Phodopus sungorus. Mammalian Species 595 1-9.

Schum JE \& Wynne-Edwards KE 2005 Estradiol, progesterone and testosterone in paternal and non-paternal hamsters (Phodopus) becoming fathers: conflict with hypothesized roles. Hormones and Behavior 47 410-418.

Scribner SJ \& Wynne-Edwards KE 1994a Thermal constraints on maternal behavior during reproduction in dwarf hamsters (Phodopus). Physiology and Behavior 55 897-903.

Scribner SJ \& Wynne-Edwards KE 1994b Disruption of body temperature and behavior rhythms during reproduction in dwarf hamsters (Phodopus). Physiology and Behavior 55 361-369.

Shaw D \& Goldman BD 1995 Gender differences in influence of prenatal photoperiods on postnatal pineal melatonin rhythms and serum PRL and FSH in the Siberian hamster (Phodopus sungorus). Endocrinology 136 4237-4246.

Sokolov VE, Cherepanova EV, Safronova LD \& Vasilieva NY 1998 Anomalies of meiosis in interspecific hybrids of Phodopus sungorus and Phodopus campbelli. Zoologicheskii Zhurnal 77 355-363.
Thomas CD, Cameron A, Green RE, Bakkenes M, Beaumont LJ, Collingham YC, Erasmus BFN, de Siqueira MF, Grainger A, Hannah L et al. 2004 Extinction risk from climate change. Nature 427 145-148.

Timonin ME \& Wynne-Edwards KE 2006 Neither reduced photoperiod, nor female-related social cues, nor increased maternal thermal stress result in a paternally responsive Phodopus sungorus male. Physiology \& Behavior 88 309-316.

van den Hurk R, Dijkstra G \& De Jong FH 2002 Enhanced serum oestrogen levels and highly steroidogenic, luteinized atretic follicles in the ovaries of the Djungarian hamster (Phodopus sungorus) kept under a short photoperiod from birth. European Journal of Endocrinology 147 701-710.

Vella ET, Evans CC, Ng MW \& Wynne-Edwards KE 2005 Ontogeny of the transition from killer to caregiver in dwarf hamsters (Phodopus campbelli) with biparental care. Developmental Psychobiology 46 75-85.

Walton JM \& Wynne-Edwards KE 1997 Paternal care reduces maternal hyperthermia in Djungarian hamsters (Phodopus campbelli). Physiology and Behavior 63 41-47.

Wilson RJ, Gutierrez D, Gutierrez J, Martinez D, Agudo R \& Monserrat VJ 2005 Changes to the elevational limits and extent of species ranges associated with climate change. Ecology Letters 8 1138-1146.

Wynne-Edwards KE 1995 Biparental care in Djungarian but not Siberian dwarf hamsters (Phodopus). Animal Behaviour 50 1571-1585.

Wynne-Edwards KE 1998 Evolution of parental care in Phodopus: conflict between adaptations for survival and adaptations for rapid reproduction. American Zoologist 38 238-250.

Wynne-Edwards KE 2003 From dwarf hamster to daddy: the intersection of ecology, evolution, and physiology that produces paternal behavior. Advances in the Study of Behavior 32 207-261.

Wynne-Edwards KE \& Lisk RD 1988 Differences in behavioral responses to a competitive mating situation in two species of dwarf hamster (Phodopus campbelli and P. sungorus). Journal of Comparative Psychology 102 49-55.

Wynne-Edwards KE \& Lisk RD 1989 Differential effects of paternal presence on pup survival in two species of dwarf hamster (Phodopus sungorus and P. campbelli). Physiology and Behavior 45 465-469.

Wynne-Edwards KE, Surov AV \& Telitzina AY 1999 Differences in endogenous activity within the genus Phodopus. Journal of Mammalogy $\mathbf{8 0} 855-865$.

Yellon SM \& Goldman BD 1984 Photoperiod control of reproductive development in the male Djungarian hamster (Phodopus sungorus). Endocrinology 114 664-670.

Received 3 May 2006

First decision 28 June 2006

Accepted 14 July 2006 